Research Article

\title{
Effects of PET Fibers on Pumpability, Shootability, and Mechanical Properties of Wet-Mix Shotcrete
}

\author{
Xiangfei Cui, ${ }^{1,2}$ Guoming Liu $\mathbb{D}^{2,3}$ Cheng-long Wang $\mathbb{D}^{1,4}$ and Yudong $\mathrm{Qi}^{2,3}$ \\ ${ }^{1}$ State Key Laboratory of Mining Disaster Prevention and Control Co-Founded by Shandong Province and \\ the Ministry of Science and Technology, Shandong University of Science and Technology, Qingdao 266590, China \\ ${ }^{2}$ College of Mining and Safety Engineering, Shandong University of Science and Technology, Qingdao 266590, China \\ ${ }^{3}$ National Demonstration Center for Experimental Mining Engineering Education, \\ Shandong University of Science and Technology, Qingdao 266590, China \\ ${ }^{4}$ College of Mechanical and Electronic Engineering, Shandong University of Science and Technology, Qingdao 266590, China
}

Correspondence should be addressed to Guoming Liu; lgmrenqing@163.com and Cheng-long Wang; wclcm@sdust.edu.cn

Received 6 June 2019; Accepted 2 July 2019; Published 28 November 2019

Academic Editor: Amir Si Larbi

Copyright (c) 2019 Xiangfei Cui et al. This is an open access article distributed under the Creative Commons Attribution License, which permits unrestricted use, distribution, and reproduction in any medium, provided the original work is properly cited.

Polyethylene terephthalate (PET) fiber from waste plastic bottles is an environmentally friendly fiber that can improve the mechanical properties of wet-mix shotcrete. The main objective of this paper is to investigate the effects of PET fiber parameters on pumpability, shootability, and mechanical properties of wet-mix shotcrete. For this purpose, the orthogonal test based on three factors and three levels was conducted. The width, length, and content of PET fiber were selected as the experimental variables. The tests of wet-mix shotcrete reinforced by PET fibers were carried out, along with properties tests such as slump, pressure drop, build-up thickness, compressive strength, and splitting strength. The results showed the change trend of shotcrete performances with increasing PET fiber parameters (width, length, and content). According to the orthogonal test, PET fiber parameters were determined ( $1 \mathrm{~mm}$ width, $20 \mathrm{~mm}$ length, and $5 \mathrm{~kg} / \mathrm{m}^{3}$ content). Furthermore, relationships between slump and pumpability and shootability were explored, as well as the relationships between pumpability, shootability, and mechanical properties. It was found that pressure drop and compressive strength had the strongest negative linear relationship among all fitting relationships. We hoped that this study could contribute the useful information for the application of wet-mix shotcrete mixed with PET fibers.

\section{Introduction}

Shotcrete technique is widely used in the repair industry, underground support, slope stabilization, and in some areas that are difficult to reach with conventional concrete [1-5]. In some engineering applications, shotcrete suffers the pressure from the surrounding environment, such as the surrounding rock in mining roadway. This pressure may cause cracks in the concrete matrix. In addition, moisture loss caused by evaporation also creates the chance for the plastic shrinkage cracking [6-8]. The most effective technique of mitigating concrete cracking is by reinforcing shotcrete with fibers. Randomly distributed fibers in concrete provide bridging forces across cracks and thus improve the concrete strength [9-12]. So far, different types of fibers have been used in reinforced concrete. These fibers are divided into synthetic and natural fibers.

Of all fibers used today, waste polyethylene terephthalate (PET) fiber is considered to the ecofriendly fiber. PET fiber is made from the recycle PET bottles such as beverage bottles. They have been proven to effectively reduce shrinkage and to enhance the ductility of concrete [13-17]. Recently, the environmental benefits of using these waste materials will encourage engineers to use them in engineering structures such as shotcrete support [18]. The application of PET plastic fibers not only mitigates environmental pollution but also improves the performance of concrete to some extent. Reinforced concrete with PET fiber has been actively studied in construction projects. 
There are two methods for producing the PET fiber. One way is to cut a PET bottle by hand or using a mechanical cutting device $[11,13,19]$; the other is to melt the PET bottle and then pull them into monofilaments by an extruder $[15,20-23]$. The properties of PET fiber, such as physical, chemical, and mechanical features, affect the concrete reinforcement. In the literature studies $[11,19]$, the properties of PET fiber from 6 different bottle brands were studied and DSC analyses were done to explore the similarities in the thermal behavior of the PET bottle samples; FTIR spectroscopy analyses were performed to determine the structural state and homogeneity of PET fibers; tension tests of PET fibers were done by pulling the fiber along the longitudinal direction. The results showed that all the PET samples basically presented the same spectrum; only slight differences were observed in the DSC thermograms; the tensile strength had a minor variation from one sample to another (range: $108 \pm 15 \mathrm{MPa}$ ). It could be concluded that PET fibers from various plastic bottles nearly have the similar characters.

As indicated in the literature studies $[17,24]$, the use of PET fibers could improve the mechanical properties of concrete mixture. Foti [19] studied the effects of lamellar and ring-shaped PET fibers on concrete ductility; the results showed that the special ring shape helped to bind the concrete on each side of a cracked section. Thereby, the addition of a very small amount of ring-shaped PET fibers could produce the large influence on the toughness of concrete mixtures. Irwan et al. [17] found that mixing PET fibers in concrete enhanced the splitting tensile strength and compressive strength. Fadhil and Yaseen [25] reported that when compared with plain concrete, the rupture strength and impact resistance of concrete panel mixed with PET fibers increased by $34.27 \%$ and $157.14 \%$, respectively. In addition, PET fibers were usually added into the asphalt mixture or bitumen, and the results showed that adding PET fibers increased the resistance to permanent deformation and rutting of substrate [14, 26-28]. Khalid et al. [29] investigated the pullout strengths of PET fibers in a concrete matrix by conducting splitting tensile and pullout tests; the author found that the incorporation of high-volume PET fiber activated the failure resistance mechanisms and thereby improved the tensile strength of concrete; it was also found that ring-shaped PET fibers performed better than irregularly shaped PET. Juhász et al. $[30,31]$ stated that the length of fiber played a key role in fiber-reinforced concrete. The authors found that the pullout strength increased when increasing the embedded length of fibers. The pullout strength was also related to the surface friction and interfacial bond energy between fibers and concrete matrix [32-34].

On the contrary, Irwan et al. [35] introduced different volumes of PET fibers $(0 \%, 0.5 \%, 1.0 \%$, and $1.5 \%)$ into concrete specimens and found that the addition of PET fibers significantly decreased the splitting tensile and compressive strength. Luckily, the compressive strength reduced by PET fibers was still within acceptable limits. Kim et al. [36] also indicated that the compressive strength and elastic modulus both decreased as PET fiber volume fraction increased in concrete mixtures.
Apart from the aforementioned studies, very few studies were conducted on the application PET fibers in wet-mix shotcrete. Wet-mix shotcrete can improve the stability of surrounding rock in underground roadway, which reduces the mine disasters such as pneumoconiosis, roof collapse, and so on [37-53]. Specifically, the pumpability and shootability of wet-mix shotcrete reinforced by PET fiber were rarely reported. This study was performed to investigate the effects of PET fiber geometry and content on the workability (i.e., slump, pressure drop, and build-up thickness) and mechanical properties (i.e., compressive strength and splitting strength) of wet-mix shotcrete. Buildup thickness refers to the maximum thickness of concrete sprayed on the wall without falling off in the process of spraying fresh concrete. The possibility of developing an alternative fiber material with healthy and ecofriendly qualities was estimated. Furthermore, the orthogonal test was used to determine the optimal PET fiber parameters. It was hoped to develop a type of wet-mix shotcrete reinforced by PET fibers with sufficient workability and mechanism to meet the standards of shotcrete support in mine roadway.

\section{Experimental Program}

2.1. Materials. A PO.42.5 Ordinary Portland cement (OPC) was used with a fineness of $3100 \mathrm{~cm}^{2} / \mathrm{g}$ and a specific gravity of 3.14. The main chemical composition of cement included $57.6 \% \mathrm{CaO}, 19.5 \% \mathrm{SiO}_{2}, 6.45 \% \mathrm{Al}_{2} \mathrm{O}_{3}, 3.08 \% \mathrm{Fe}_{2} \mathrm{O}_{3}, 2.01 \%$ $\mathrm{SO}_{3}$, and $1.3 \% \mathrm{MgO}$.

Crushed limestone as coarse aggregate was used with a maximum size of $10 \mathrm{~mm}$. Fine aggregate was natural river sand. The fineness moduli of crushed limestone and sand were 5.70 and 2.66, respectively. The specific gravities of crushed limestone and sand were 2.67 and 2.61, respectively. The water absorption of coarse and fine aggregates was considered to correct the water consumption. Figure 1 shows the gradation curves for both fine and coarse aggregates that complied with the requirement in national standard GB50086-2001 (Specifications for Bolt-Shotcrete Support). A WT-N1-type nonalkali liquid accelerator was introduced into wet-mix shotcrete to improve the shootability. The physical properties of the accelerator are presented in Table 1. Table 1 and Figure 1 are reproduced from Liu et al. [12].

2.2. PET Fiber. PET fibers were obtained by cutting the waste PET bottles, as shown in Figure 2. The fiber dimensions were $1 \mathrm{~mm}, 2 \mathrm{~mm}$, and $3 \mathrm{~mm}$ in width, as well as $10 \mathrm{~mm}, 20 \mathrm{~mm}$, and $30 \mathrm{~mm}$ in length. The thickness of all PET fibers was $0.34 \mathrm{~mm}$. In order to ensure the consistency of experimental variables, PET fibers were cut from the same type bottle of Laoshan mineral water bottle. According to the previous experiments $[11,13,17]$, Young's modulus was $3830 \pm 47 \mathrm{MPa}$, the tensile strength was $108 \mathrm{MPa}$, and the calculated degree of crystallinity was $23 \pm 1 \%$.

2.3. Mixture Composition and Tests. The basic mix proportion used in this study was fixed in terms of cement, 


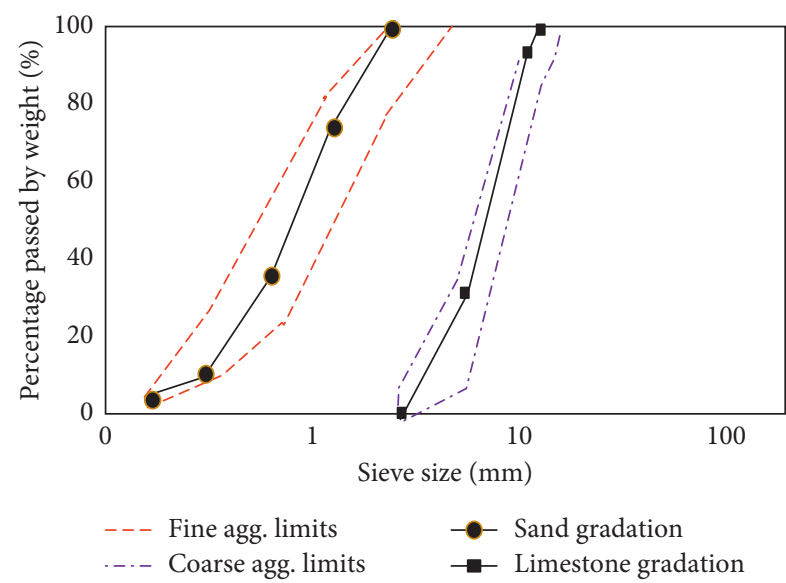

Figure 1: Gradation curves for crushed limestone and river sand.

water, and coarse and fine aggregates. But the content of PET fibers was variable $\left(5,7,9 \mathrm{~kg} / \mathrm{m}^{3}\right)$. Table 2 listed the mix proportion of wet-mix shotcrete. Note that the mixture proportions used in this study were based on practical experiments and literature studies [12, 13, 54, 55].

The Taguchi method (we called "orthogonal test") was applied as a process optimization technique to seek the optimal parameters of PET fiber. The Taguchi method was developed by Genichi Taguchi during the 1950s [56], which uses orthogonal arrays from design of experiments theory to study a large number of variables with a small number of tests. In order to analyze comprehensively the influence of PET fiber parameters on the pumpability, shootability, and hardenability of wet-mix shotcrete, the effects of length, width, and content of PET fibers on slump, pressure drop, build-up thickness, compressive strength, and splitting tensile strength of wet-mix shotcrete were investigated in this study. Table 3 lists the variables and levels used in the study, and Table 4 shows the $\mathrm{L}_{9}\left(3^{4}\right)$ orthogonal array for the Taguchi method. The $\mathrm{L}_{9}\left(3^{4}\right)$ orthogonal array means that nine experiments are needed and four variables can be observed. Since there were only three variables (length, width, and content) in our experiment, according to the principle of orthogonal experimental design, a blank column was added to satisfy the requirement of $\mathrm{L}_{9}\left(3^{4}\right)$ orthogonal array.

2.4. Tests of Pumpability, Shootability, and Mechanical Properties. Pumpability of fresh concrete meant that the concrete mixtures could flow in pipes without blockage [57-59]; Shootability was regarded as the ability of fresh concrete to be sprayed with suitable cohesion and adhesion [59-61]. The slump value could reflect these two abilities of fresh concrete. Relatively large slump and small pressure drop implied the good pumpability; relatively low slump and large build-up thickness could indicate good shootability. Although the rebound rate could express the shooting ability of concrete, given that previous literature studies $[62,63]$ ever reported that the fiber geometry or fiber mass had no significant influence on the rebound rate, we did not carry out the rebound experiment for the wet-mix shotcrete mixed with PET fibers. Therefore, only slump and build-up thickness tests were conducted to estimate the shootability.

Slump tests were conducted after mixing concrete mixtures well near the pump. A double plunger pump (Model: SPB7-T) was used to carry out the test of wet-mix shotcrete. The maximum pumping flow was $7 \mathrm{~m}^{3} / \mathrm{h}$. The rated pressure of the hydraulic system of the double pump was $16 \mathrm{MPa}$. The pressure sensors were installed at different distances along the pumping pipes, as shown in Figure 3. The pressure drop was calculated by using equation (1), where $P_{1}$ and $P_{2}$ means the pressure measured at different distances; $L$ means the pipeline length between two pressure sensors; and $\Delta p$ means the pressure drop $(\mathrm{kPa} / \mathrm{m})$. Segregation and bleeding were not observed during the slump test:

$$
\Delta p=\frac{\left(P_{2}-P_{1}\right)}{L} \text {. }
$$

In order to estimate the mechanical properties of wetmix shotcrete reinforced by PET fibers, the fresh concrete mixtures were firstly sprayed into big ironbox molds. Sprayed concrete was demoulded after 1-day curing at the standard curing chamber with a temperature of $20 \pm 2^{\circ} \mathrm{C}$ and 95\% relative humidity. After 7 days curing, the concrete slab was cut into standard cube specimens with dimensions $100 \mathrm{~mm} \times 100 \mathrm{~mm} \times 100 \mathrm{~mm}$. Finally, specimens were cured at standard condition to 28 days. The uniaxial compressive strength and splitting tensile strength of specimens were measured using the electric universal test machine. Figure 4 shows the experimental procedure including shotcrete test (a), measurement of build-up thickness (b), compressive test (d), and splitting test (e). All tests followed the Professional Standards of China (DL/T 5181-2003: construction specifications for anchor and shotcrete support of hydropower and water conservancy engineering).

\section{Results and Discussion}

3.1. Results of Orthogonal Test. The feasible levels of PET fiber parameters (length, width, and content) were studied by the orthogonal test for the minimization of pressure drop and for the maximization of build-up thickness, compressive strength, and splitting strength. Table 5 lists the ranges of measured properties of wet-mix shotcrete, slump of 9$18 \mathrm{~cm}$, pressure drop of $25-40 \mathrm{kPa} / \mathrm{m}$, build-up thickness of $13.3-17.6 \mathrm{~cm}$, compressive strength of $36.2-47.6 \mathrm{MPa}$, and splitting strength of 3.8-4.9 MPa. Those test data of wet-mix shotcrete properties were studied by the analysis of variance (ANOVA) at a 0.05 level of significance. The interactive effects of the fiber parameters were neglected.

Figures 5-11 show the main effect graphs of slump, pressure drop, build-up thickness, splitting strength, and compressive strength. The variations in PET fiber parameters were treated as independent variables, whereas the rheological properties (slump), pumpability (pressure drop), shootability (build-up thickness), and mechanical properties (compressive and splitting strengths) of wet-mix shotcrete were regarded as dependent variables in Table 5 . The analysis data of ANOVA such as the contribution percentage of factors, DEVSQ, and statistically significant factors are listed 
TABLE 1: Physical properties of the WT-N1-type nonalkali liquid accelerator.

\begin{tabular}{lccccc}
\hline Appearance & $\begin{array}{c}\text { Initial setting } \\
\text { time }(\mathrm{min})\end{array}$ & $\begin{array}{c}\text { Final setting } \\
\text { time (min) }\end{array}$ & Solid-containing content (\%) & Active component & Mixing amount (\%) \\
\hline Brownish liquid & $2-3$ & $7-9$ & 61.4 & Aluminum sulfate \\
\hline
\end{tabular}

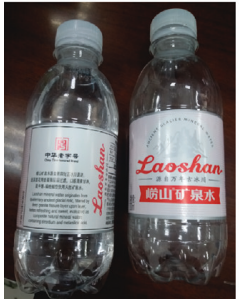

Waste PET bottles

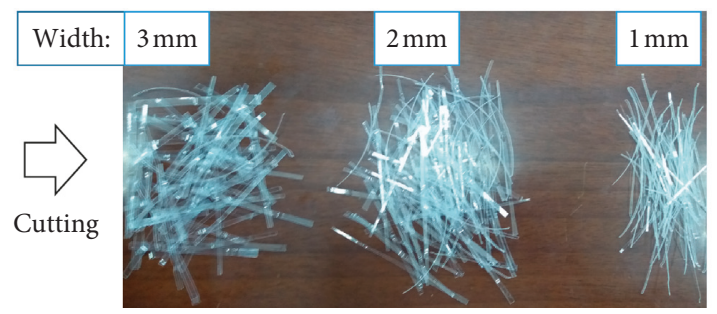

PET fibers

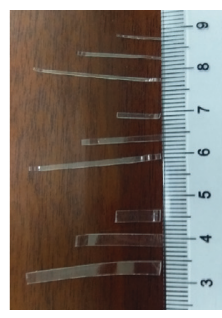

Length: $1 / 2 / 3 \mathrm{~cm}$

Figure 2: Cutting PET bottles for PET fibers.

TABLE 2: Mix proportion of wet-mix shotcrete $\left(\mathrm{kg} / \mathrm{m}^{3}\right)$.

\begin{tabular}{lccccc}
\hline Cement & Water & Coarse aggregate & Fine aggregate & Accelerator & PET fiber \\
\hline 440 & 220 & 600 & 1000 & 22 & $5 / 7 / 9$ \\
\hline
\end{tabular}

TABLE 3: Levels of variables used in orthogonal test.

\begin{tabular}{lccc}
\hline Variable & $\begin{array}{c}\text { Fiber width } \\
(\mathrm{mm})\end{array}$ & $\begin{array}{c}\text { Fiber length } \\
(\mathrm{mm})\end{array}$ & $\begin{array}{r}\text { Fiber content } \\
\left(\mathrm{kg} / \mathrm{m}^{3}\right)\end{array}$ \\
\hline Level 1 & 1 & 10 & 5 \\
Level 2 & 2 & 20 & 7 \\
Level 3 & 3 & 30 & 9 \\
\hline
\end{tabular}

TABLE 4: Details of mix proportions in the $\mathrm{L}_{9}$ orthogonal array.

\begin{tabular}{|c|c|c|c|c|}
\hline \multirow{2}{*}{ Experimental no. } & \multicolumn{4}{|c|}{ Independent variables } \\
\hline & Blank & Width & Length & Content \\
\hline No. 1 & 1 & 1 & 1 & 1 \\
\hline No. 2 & 1 & 2 & 2 & 2 \\
\hline No. 3 & 1 & 3 & 3 & 3 \\
\hline No. 4 & 2 & 1 & 2 & 3 \\
\hline No. 5 & 2 & 2 & 3 & 1 \\
\hline No. 6 & 2 & 3 & 1 & 2 \\
\hline No. 7 & 3 & 1 & 3 & 2 \\
\hline No. 8 & 3 & 2 & 1 & 3 \\
\hline No. 9 & 3 & 3 & 2 & 1 \\
\hline
\end{tabular}

in Table 6. Note that the contribution percentage of various factors represented the degree of influence of the corresponding factors on the measured properties of wet-mix shotcrete. The higher contribution percentage meant the more contribution of the factor on the measured response. According to the orthogonal analysis, the advised PET fiber parameters for target properties of wet-mix shotcrete are shown in Table 7.

3.2. Discussion. Slump was a traditional rheological parameter that could estimate the flowability of wet-mix shotcrete. The higher slump value implied the bigger flowability of fresh concrete; that was to say, the pumpability of fresh concrete with larger slump was good when fresh concrete flowed in pipes. Conversely, the large flowability was not beneficial for the build-up thickness, which implied the bad shootability of fresh concrete. Therefore, the appropriate slump value was important for wet-mix shotcrete to guarantee the accepted pumpability and shootability simultaneously.

Figure 5 indicates that the slump increased with increasing fiber width; the PET fiber with $3 \mathrm{~mm}$ width significantly improved the fluidity of fresh concrete. Slump value showed a tendency to decrease with the increase of the fiber length or fiber content, these results were similar to the reports in $[58,60]$. Table 6 lists the analysis of variance results; PET fiber length was the most influencing factor on slump with $57.91 \%$ contribution. The least influencing factor was PET fiber content with $8.42 \%$ contribution. Combined with the data in the Table 5 where the No. 6 concrete sample shows the highest slump, whereas the No. 4 sample gives the lowest slump value, it was found that the slim PET fiber tended to agglomerate concrete aggregates, reducing its fluidity; on the contrary, the PET fibers with large width and short length exhibited a similar effect to the circular aggregate, which increased the slump due to the smooth surface. When considering the pumping and shooting performance of fresh concrete comprehensively, slump was recommended at a middle value; hence the parameters of PET fiber used for wet-mix shotcrete was $1 \mathrm{~mm}$ (or $2 \mathrm{~mm}$ ) width, $20 \mathrm{~mm}$ length, and $7 \mathrm{~kg} / \mathrm{m}^{3}$ content.

Pressure drop was the most intuitive parameter to indicate the pumpability of fresh concrete. Small pressure drop meant less flow resistance (i.e., better pumpability) when fresh concrete flowed in pipes $[13,64]$. According to Figure 6, pressure drop increased with increasing fiber width or with increasing fiber content but decreased with the 


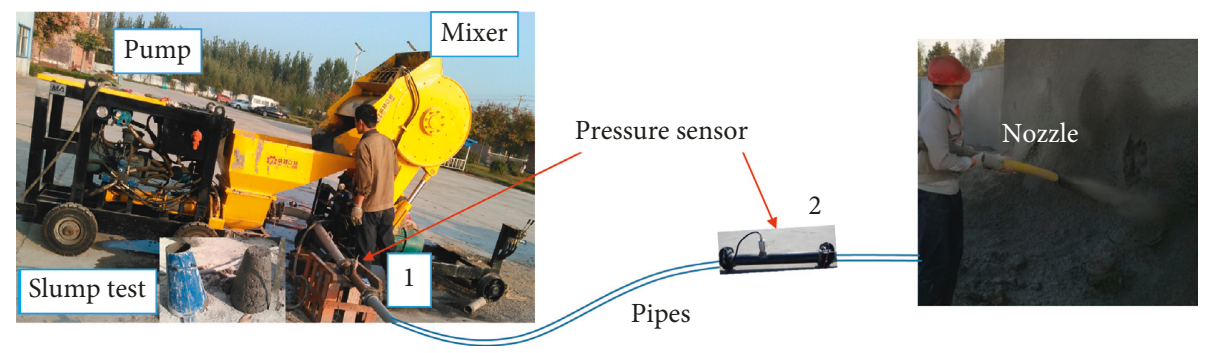

FIgURE 3: Wet-mix shotcrete test (slump test, pressure measurement, and shotcreting).
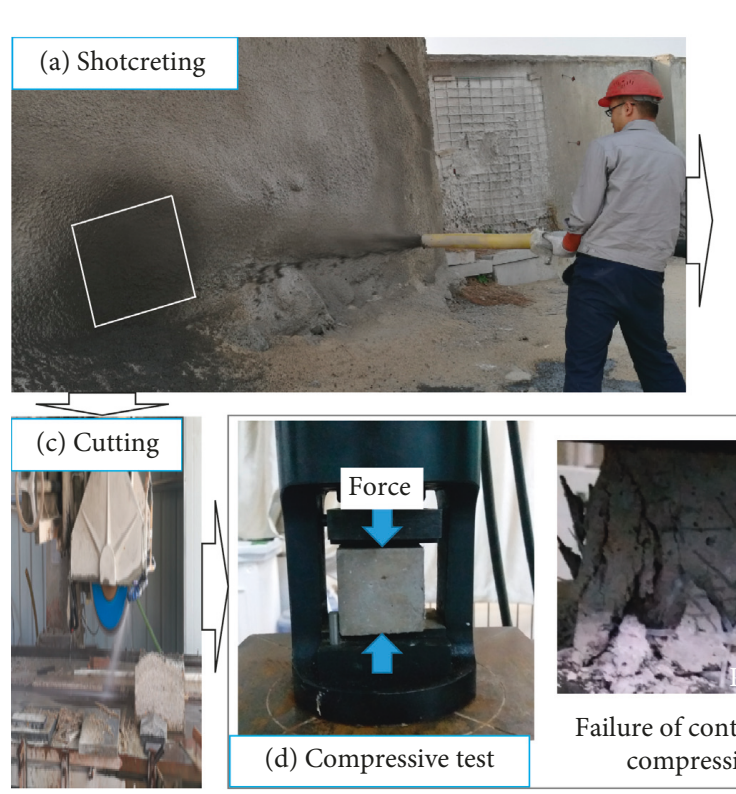

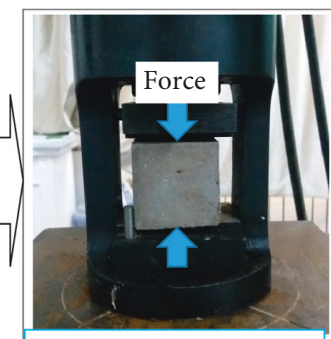

(d) Compressive test

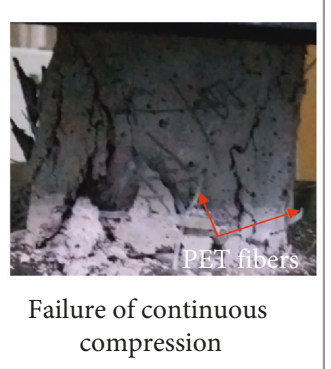

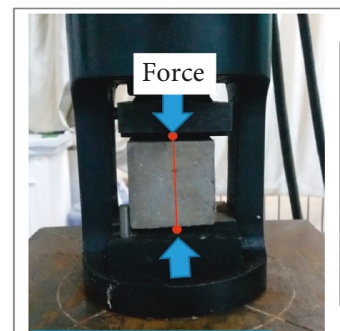

(e) Splitting test (b) Build-up thickness
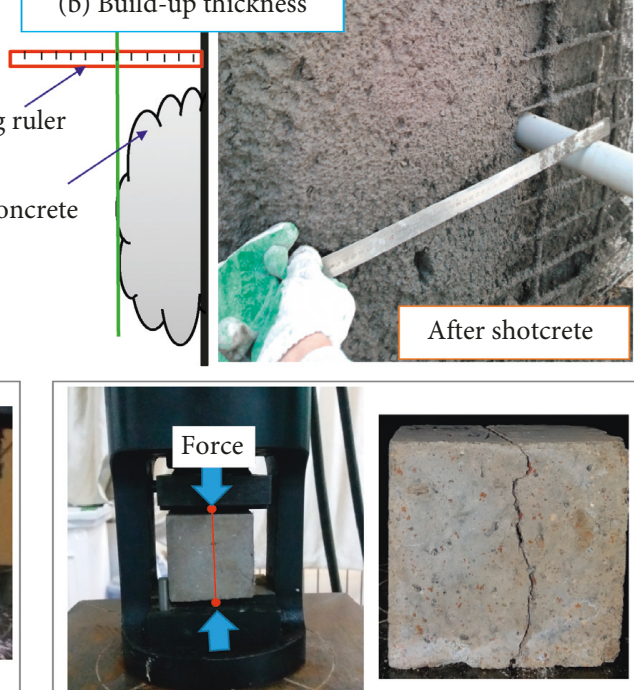

Splitting failure

FIGURE 4: Measurement of build-up thickness and tests of mechanism properties of wet-mix shotcrete.

TABLE 5: Results of orthogonal tests for wet-mix shotcrete reinforced by PET fibers.

\begin{tabular}{|c|c|c|c|c|c|c|c|c|}
\hline No. & Width (mm) & Length (mm) & Content $\left(\mathrm{kg} / \mathrm{m}^{3}\right)$ & Slump $(\mathrm{cm})$ & $\begin{array}{l}\text { Pressure drop } \\
\quad(\mathrm{kPa} / \mathrm{m})\end{array}$ & $\begin{array}{c}\text { Build-up } \\
\text { thickness }(\mathrm{cm})\end{array}$ & $\begin{array}{l}\text { Compressive } \\
\text { strength (MPa) }\end{array}$ & $\begin{array}{c}\text { Splitting strength } \\
(\mathrm{MPa})\end{array}$ \\
\hline 1 & 1 & 10 & 5 & 16 & 25 & 13.8 & 47.6 & 3.8 \\
\hline 2 & 2 & 20 & 7 & 12 & 30 & 15.8 & 44.3 & 4.3 \\
\hline 3 & 3 & 30 & 9 & 13 & 38 & 17.2 & 36.2 & 4.6 \\
\hline 4 & 1 & 20 & 9 & 9 & 30 & 16.0 & 45.1 & 4.7 \\
\hline 5 & 2 & 30 & 5 & 10 & 27 & 17.6 & 46.2 & 4.9 \\
\hline 6 & 3 & 10 & 7 & 18 & 40 & 14.7 & 39.6 & 3.9 \\
\hline 7 & 1 & 30 & 7 & 11 & 28 & 16.0 & 46.3 & 4.8 \\
\hline 8 & 2 & 10 & 9 & 14 & 33 & 15.5 & 42.7 & 4.4 \\
\hline 9 & 3 & 20 & 5 & 15 & 35 & 13.3 & 38.1 & 4.0 \\
\hline
\end{tabular}

increase of PET fiber length. With $80.24 \%$ contribution, PET fiber width was the most effective parameter on the pressure drop. The second most influencing factor was PET fiber content with $17.7 \%$ contribution. The length of PET fiber produced the least influence on pressure drop.

The lowest and highest pressure drops were measured in No. 1 and No. 6 concrete sample, respectively. According to analysis, the thin and long fibers tended to agglomerate the concrete, thus avoiding the segregation and bleeding of fresh concrete under the pumping action. In addition, the concrete plunger in the conveying pipes became very stable.
With the help of the slip layer near the inner pipe wall, the agglomerated concrete with slim PET fibers was transported in the form of slip rather than shear in the pipe, as shown in Figure 7. The optimal PET fiber parameters for minimization of pressure drop were $1 \mathrm{~mm}$ width, $30 \mathrm{~mm}$ length, and $5 \mathrm{~kg} / \mathrm{m}^{3}$ content.

Figure 8 shows that when the length and content of PET fibers increased, the build-up thickness increased. This result was convenient to the literature studies $[1,12,65,66]$. According to analysis, on the one hand, the addition of PET fibers enhanced the yield stress of the concrete sprayed on 

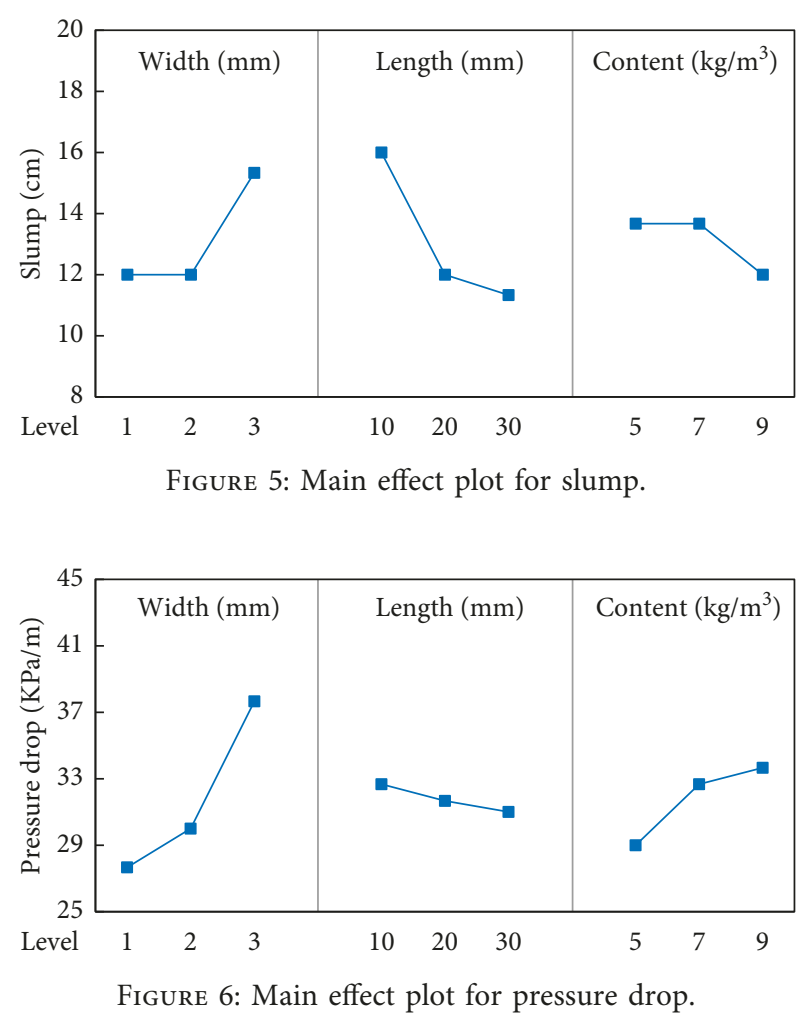

the wall and the high yield stress could reduce the collapse of concrete $[60,67]$. On the other hand, due to the knifing effect of fibers, concrete aggregates were tightly reunited together. With increasing fiber length and content, two effects were strengthened, and thus, build-up thickness was increased. The build-up thickness firstly increased and then declined with increase in the fiber width. An excessively wide fiber did not increase the consistency of the sprayed concrete. In addition to the influence of smooth surface of wide fibers, the agglomeration effect of wide fibers on concrete was weakened. PET fiber length was the most effective factor on the build-up thickness with $62.6 \%$ contribution. The width and content of PET fibers had the similar contribution on the build-up thickness with $18.57 \%$ and $18.87 \%$, respectively. The optimal parameters of PET fibers used for the maximum build-up thickness of wet-mix shotcere were $2 \mathrm{~mm}$ width, $30 \mathrm{~mm}$ length, and $9 \mathrm{~kg} / \mathrm{m}^{3}$ content.

Figure 9 indicates that increasing the width and content of PET fiber reduced the compressive strength of wet-mix shotcrete. The negative effect of PET fibers on compressive strength was similar to other types of fibers such as polypropylene fiber [12] and steel fiber [68]. Irwan et al. [35] and Kim et al. [36] even reported the same results that PET fiber did not significantly increase the compressive strength of concrete but the strength range of concrete mixed with PET fibers was accepted in the special application of engineering. The length of PET fiber from $10 \mathrm{~mm}-30 \mathrm{~mm}$ did not produce big impact on compressive strength. The most influencing factor on compressive strength was PET fiber width with $90.21 \%$ contribution; PET fiber content was the second most influencing factor with $9.03 \%$ contribution. According to the analysis in Figure 10, the wide fiber with smooth surface promoted the slip effect between aggregates when concretes were compressed; this phenomenon reduced the compressive strength of hardened concretes, whereas the narrow fiber with $1 \mathrm{~mm}$ width produced less or no slip due to its less contacting area with aggregates. The optimal PET fiber parameters for maximization of compressive strength of wet-mix shotcrete were $1 \mathrm{~mm}$ width, $10 \mathrm{~mm}$ length, and $5 \mathrm{~kg} / \mathrm{m}^{3}$ content.

Figure 11 shows that the splitting strength of wet-mix shotcrete increased with increase in the length and content of PET fiber. The main function of fibers was to prevent the crack of concrete because fibers worked as a bridge on both sides of a crack. Fibers increased the ductility and reduced the crack risk in shotcrete structures. The positive effect of fiber on splitting strength was reported $[10,68,69]$. The uniform distribution of fibers in concrete was a prerequisite for ensuring high strength of concrete. A uniform and effective fiber distribution would be achieved when fiber length was less than the coarse aggregate size. However, in order to improve the mechanical properties of concrete, Han et al. [70] suggested that the length of fiber should exceed 1.3 times coarse aggregate size. Olivito and Zuccarello [71] indicated that the size of coarse aggregate should not exceed 0.5 times fiber length. Increasing PET fiber width from $1 \mathrm{~mm}$ to $2 \mathrm{~mm}$ increased the splitting tensile strength of wet-mix shotcrete. But if the width of fiber was continuously increased to $3 \mathrm{~mm}$, the splitting strength would be reduced obviously. Generally, the wide fiber had a large contact area with the concrete matrix, which would enhance the friction function and further increase the splitting strength. However, the surface of wide PET fiber was very smooth, resulting in the weak adhesion between PET fibers and concrete matrix. Therefore, the increased contact area of wide PET fiber did not improve the splitting strength.

The most influencing factor on the splitting tensile strength was fiber length with $67.54 \%$ contribution; the width of PET fiber was the second most influencing factor with $17.88 \%$ contribution. The contribution rank of the variables on the slump, pressure drop, thickness, compressive strength, and splitting strength is listed in Table 6 . The optimal PET fiber parameters for maximization of splitting tensile strength of wet-mix shotcrete were $2 \mathrm{~mm}$ width, $30 \mathrm{~mm}$ length, and $9 \mathrm{~kg} / \mathrm{m}^{3}$ content.

According to the data in Table 6, in terms of statistical significance, the significant factor that appeared frequently was PET fiber width, especially for pressure drop and compressive strength. Consequently, fiber width was the first factor to consider for selecting the optimal fiber parameters. Combined with the selected parameters of PET fiber for various shotcrete properties in Table 7, the final PET fiber parameters were determined, which were $1 \mathrm{~mm}$ width, $20 \mathrm{~mm}$ length, and $5 \mathrm{~kg} / \mathrm{m}^{3}$ content, to improve the build-up thickness, compressive strength, and splitting strength and reduce the pressure drop.

In order to verify the practicality of the optimal PET fiber parameters, another experimental study was conducted to check whether the PET fiber parameters obtained could improve the properties of wet-mix shotcrete. The verification results showed that the proposed optimum PET fiber 


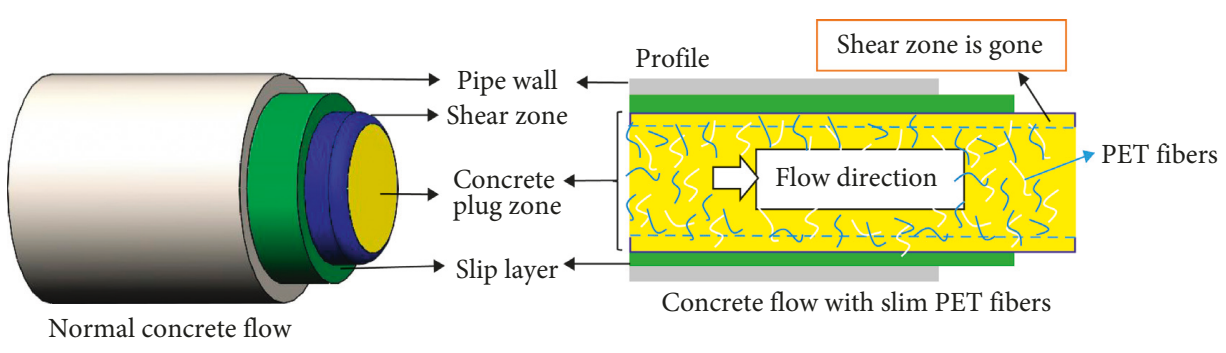

Figure 7: Changes of the flow forms of fresh concrete in pipes after mixing PET fibers.

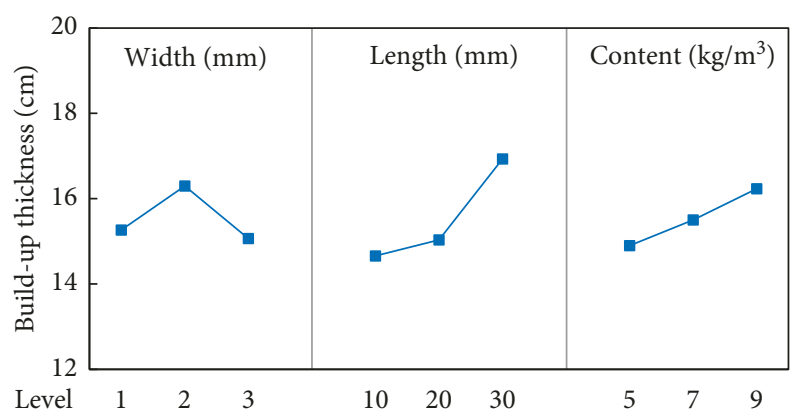

FIgURE 8: Main effect plot for build-up thickness.

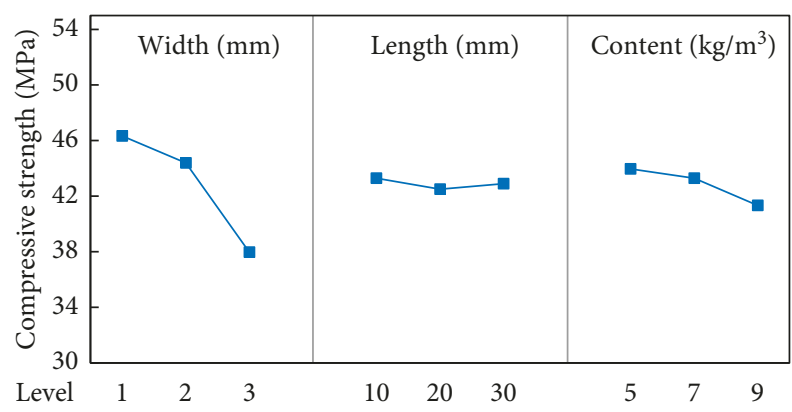

FIGURE 9: Main effect plot for compressive strength.

parameters satisfied the expected requirement: minimization for pressure drop with $24 \mathrm{kPa} / \mathrm{m}$ and relatively other better performances such as $17 \mathrm{~cm}$ build-up thickness, $43 \mathrm{MPa}$ compressive strength, and $4.5 \mathrm{MPa}$ splitting strength. In this paper, the influence of fire on the properties of shotcrete was not considered because the influence of fire on PET fiber is unfavorable. Therefore, PET fiber-reinforced shotcrete is suitable for those building structures far away from fire areas or underground roadways with short service time and relatively low strength requirements.

3.3. Correlation Analysis. In this study, we assumed that the pressure drop represented the pumpability and the build-up thickness represented the shootability of wet-mix shotcrete reinforced by PET fibers. The effects of slump on pumpability and shootability, as well as the relationships between pumpability, shootability, and mechanical properties of wetmix shotcrete, were explored, as shown in Figures 12-18. It should be pointed out that all fitting curves and fitting formulas in Figures 12-18 were only used as the trend indicators because most of the data points were too discrete and the corresponding fitting variances were too small to predict the corresponding properties of wet-mix shotcrete precisely.

3.3.1. Relationship between Slump and Pumpability and Shootability. Figure 12 shows the change laws of pressure drop and build-up thickness with increasing slump value. Although the data points were very discrete (the fitting variance is 0.2159 and 0.4787 , respectively, much less than 1), the overall trend could be observed. Pumpability of fresh shotcrete mixed with fibers showed an upward trend with increasing slump. Generally, the fresh concrete with large slump was easy to flow in pipes with less resistance $[64,72,73]$. The addition of PET fibers was the main reason why low slump concrete flowed with less resistance. As described above in Section 3.2, PET fibers agglomerated the concrete materials and thus promoted fresh concrete to form a plug flow. Fresh concrete with plug flow was easier to transport in pipes based on the formation of the sufficient lubrication layer. Shootability of wet-mix shotcrete declined with the increase of slump. According to previous research progress $[12,54,72,74,75]$, these results are predictable because large slump concrete had high fluidity that was easy to collapse on the wall surface sprayed, which was not conducive to the formation of spraying layer.

\subsubsection{Relationship between Pumpability and Mechanical} Properties. Figure 13 indicates that the change trend of compressive strength and splitting strength with increasing pressure drop. Overall, the data points were relatively discrete especially for the relationship between pressure drop and splitting strength; Both compressive and splitting strengths of wet-mix shotcrete showed a downward trend. The downtrend of compressive strength was more obvious than that of splitting strength; the corresponding fitting effect was best among all fitting functions (Figures 12-18); fitting variance was 0.8482 . Under normal circumstances, it was difficult to relate the pumpability of concrete to mechanical properties. According to analysis, a larger pressure drop meant that the pumping pressure was stronger. Alternate pumping pressure impacted the fresh concrete in pipes, resulting in the uneven distribution of coarse and fine aggregates inside the concrete plug. As shown in Figure 14, under the action of shear-induced particle migration, coarse aggregates flowed in the center of pipes, whereas fine 


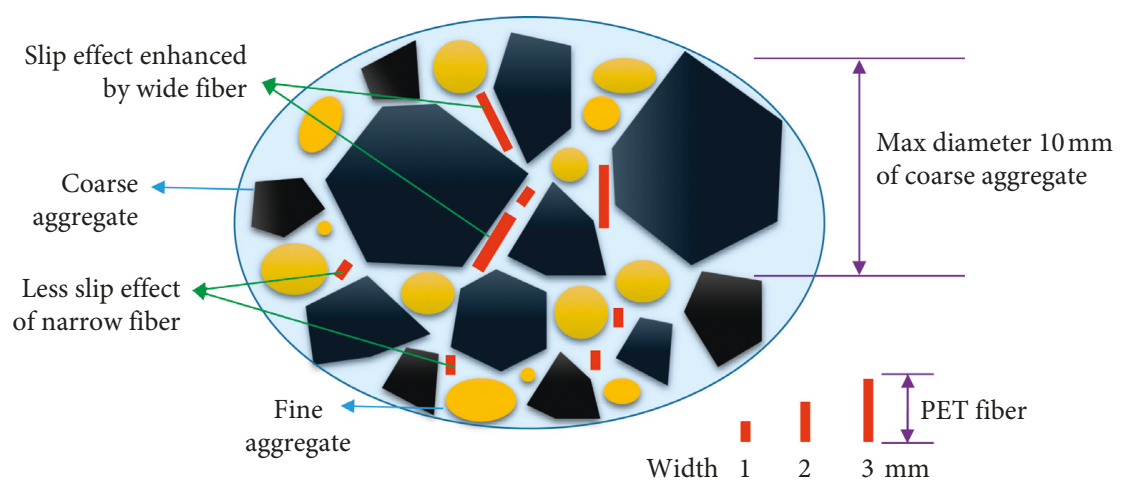

Figure 10: Schematic of the effect of PET fiber width on aggregate bonding.

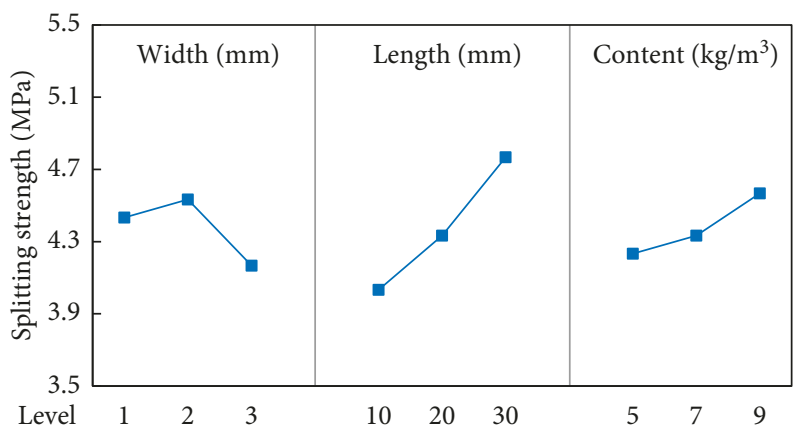

FIGURE 11: Main effect plot for splitting strength.

TABLE 6: Analysis of variance results of wet-mix shotcrete (degree of freedom: 2).

\begin{tabular}{|c|c|c|c|c|c|c|}
\hline Variable & Parameters & DEVSQ & $F$ ratio & $F$ critical value & Statistical significance & Contribution (\%) \\
\hline \multirow{4}{*}{ Slump } & Width & 22.22 & 7.69 & 19 & - & 33.67 \\
\hline & Length & 38.22 & 13.23 & 19 & - & 57.91 \\
\hline & Content & 5.55 & 1.92 & 19 & - & 8.42 \\
\hline & Error & 2.89 & - & - & - & - \\
\hline \multirow{4}{*}{ Pressure drop } & Width & 164.22 & 56.84 & 19 & Yes & 80.24 \\
\hline & Length & 4.22 & 1.46 & 19 & - & 2.06 \\
\hline & Content & 36.22 & 12.53 & 19 & - & 17.70 \\
\hline & Error & 2.89 & & & & \\
\hline \multirow{4}{*}{ Build-up thickness } & Width & 2.62 & 1.27 & 19 & - & 18.53 \\
\hline & Length & 8.88 & 4.32 & 19 & - & 62.60 \\
\hline & Content & 2.67 & 1.30 & 19 & - & 18.87 \\
\hline & Error & 2.06 & - & - & - & \\
\hline \multirow{4}{*}{ Compressive strength } & Width & 115.12 & 44.50 & 19 & Yes & 90.21 \\
\hline & Length & 0.96 & 0.37 & 19 & - & 0.75 \\
\hline & Content & 11.52 & 4.45 & 19 & - & 9.03 \\
\hline & Error & 2.59 & - & - & & - \\
\hline \multirow{4}{*}{ Splitting strength } & Width & 0.21 & 1.98 & 19 & - & 17.88 \\
\hline & Length & 0.81 & 7.48 & 19 & - & 67.54 \\
\hline & Content & 0.17 & 1.61 & 19 & - & 14.57 \\
\hline & Error & 0.11 & - & - & - & - \\
\hline
\end{tabular}

aggregates flowed near the pipe wall [76]. Further, the uneven concrete was sprayed on the receiving surface, leading to the unevenness of aggregate deposits. This phenomenon might cause the loss of concrete strength after hardening. Hence, we could imagine that larger pump pressure caused more loss of compressive and splitting strength. In addition to this, the effects of admixture should be considered. For example, an appropriate amount of fibers could reduce pumping pressure [13], but fiber might not significantly increase the strength of the concrete $[35,36]$.

3.3.3. Relationship between Shootability and Mechanical Properties. It can be seen from Figure 15(a) that the build-up 
TABLE 7: Optimal parameters of PET fiber for wet-mix shotcrete.

\begin{tabular}{lccc}
\hline Variable & Width $(\mathrm{mm})$ & Length $(\mathrm{mm})$ & Content $\left(\mathrm{kg} / \mathrm{m}^{3}\right)$ \\
\hline Slump & 3 & 10 & 5 \\
Pressure drop & 1 & 30 & 5 \\
Build-up thickness & 2 & 30 & 9 \\
Compressive strength & 1 & 10 & 5 \\
Splitting strength & 2 & 30 & 5 \\
Optimal parameters of PET fiber & 1 & 20 & 5 \\
\hline
\end{tabular}

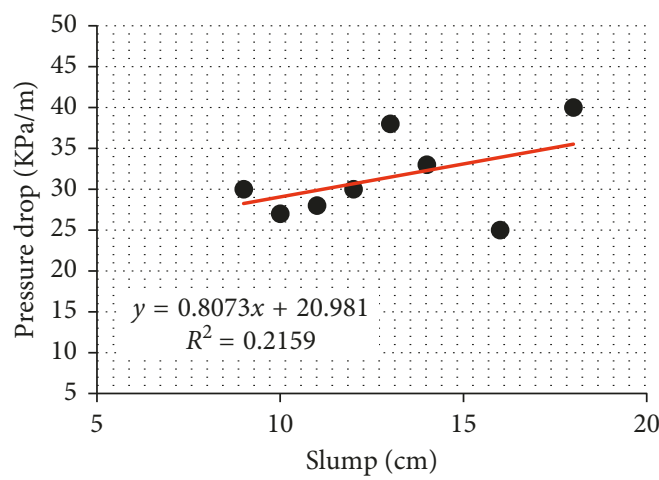

(a)

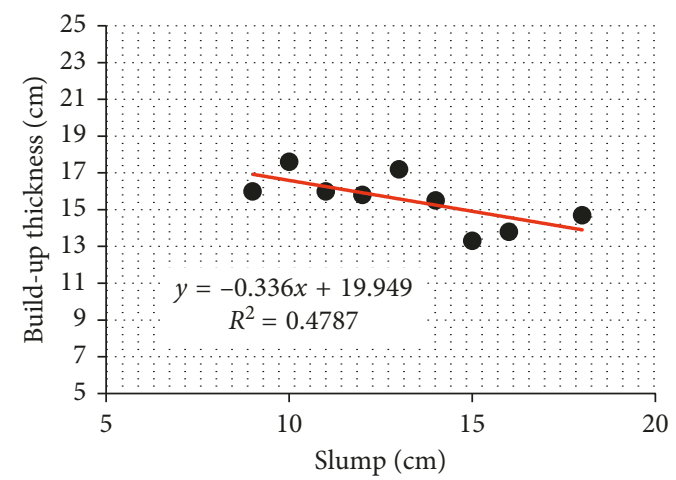

(b)

FIGURE 12: Correlation between slump and pumpability (a) and shootability (b).

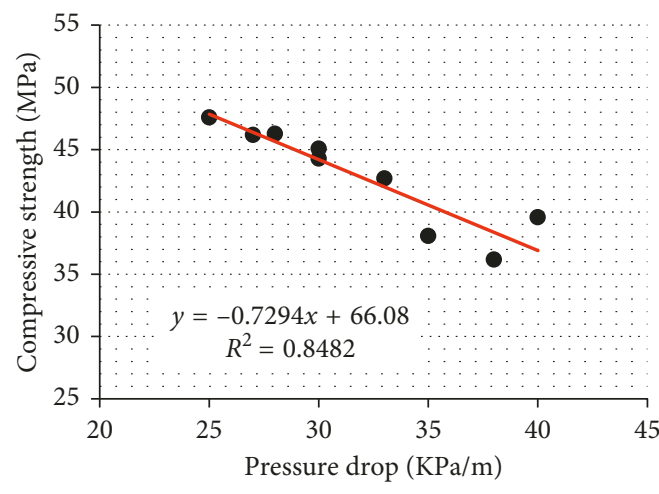

(a)

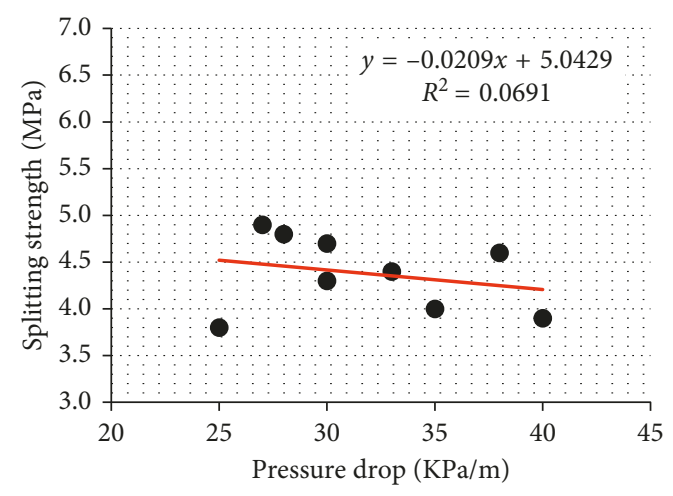

(b)

FIGURE 13: Correlation between pumpability and compressive strength (a) and splitting strength (b).

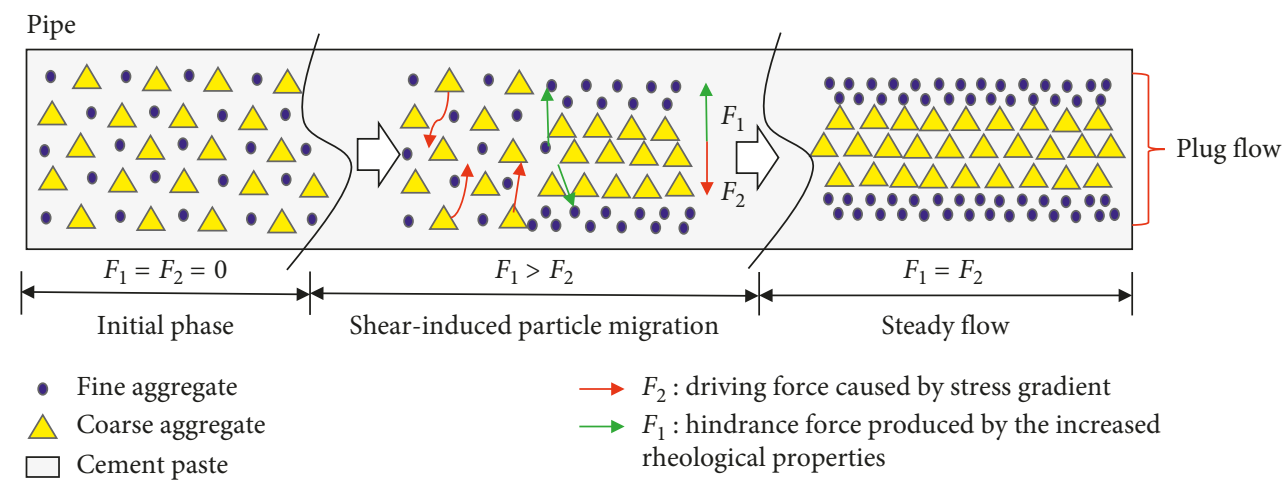

Figure 14: Aggregate distribution of fresh concrete flowing in pipes. 


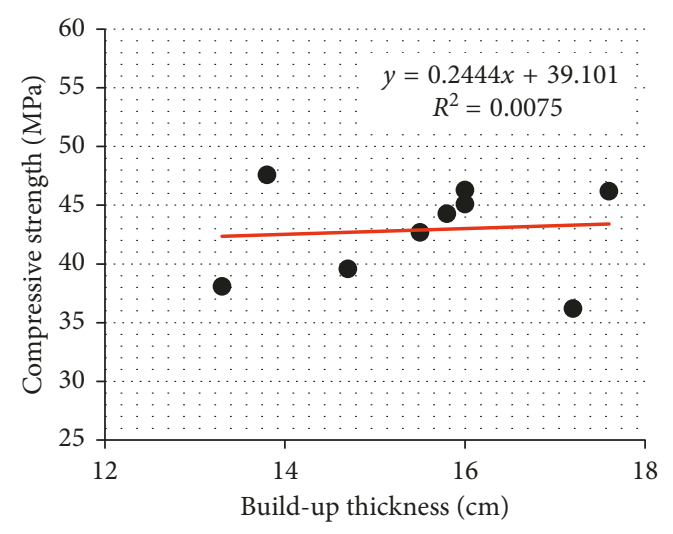

(a)

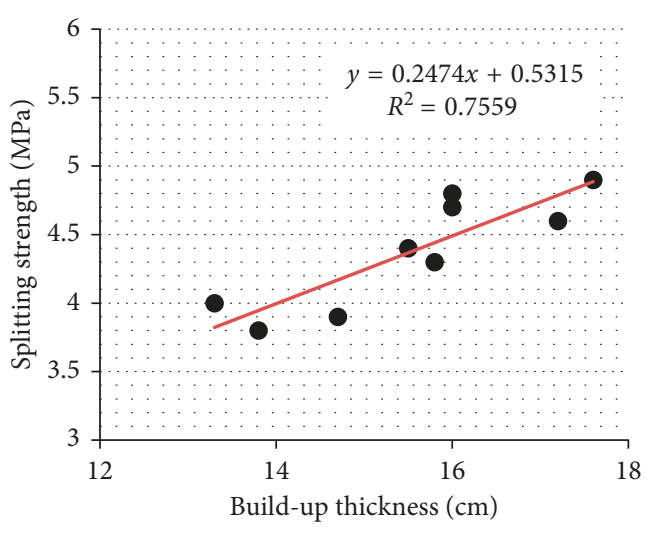

(b)

FIGURE 15: Correlation between shootability and compressive strength (a) and splitting strength (b).

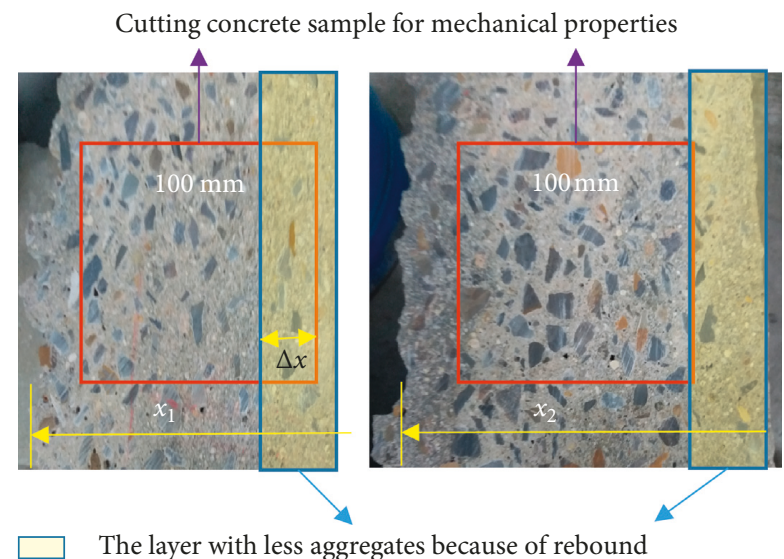

Figure 16: Cutting lines of thin and thick shotcrete layers for standard concrete specimens.

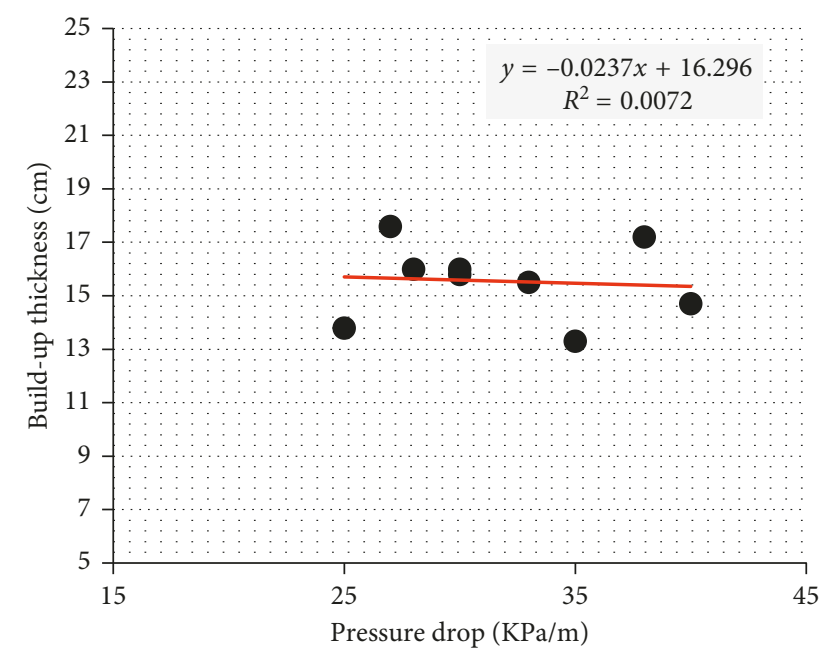

FIGURE 17: Correlation between pumpability and shootability.

thickness had less effect on compressive strength while it had relatively obvious effect on splitting strength. The splitting strength increased with the increase of build-up thickness, along with the better linear fitting variance of 0.7559 . In order

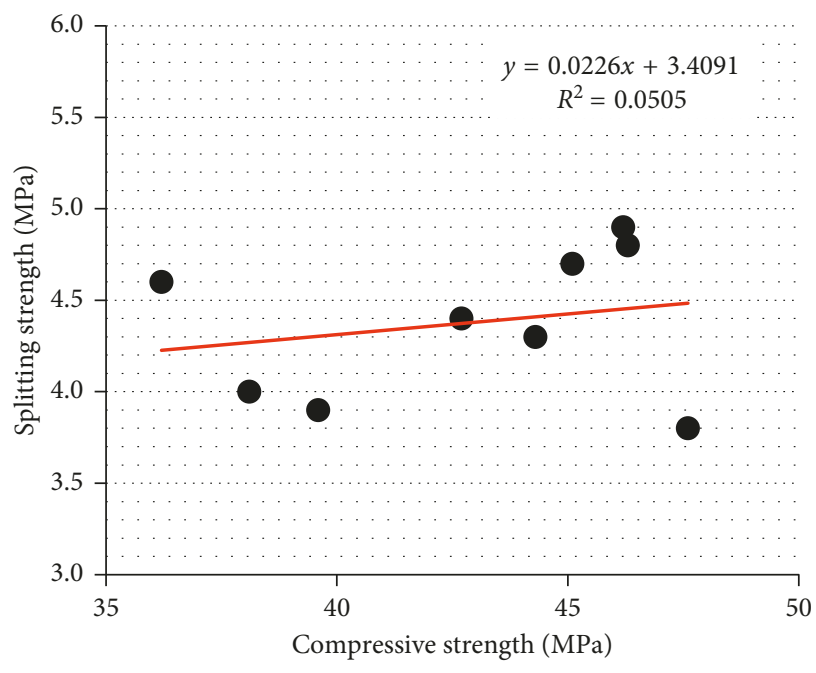

FIgURE 18: Correlation between compressive and splitting strengths.

to explore the possible reason why build-up thickness affected the mechanical properties, the aggregate distribution on the cutting surface of hardened concrete slab was analyzed along the spraying direction. As shown in Figure 16, the distribution of coarse aggregates from the receiving wall to shotcrete surface $(x)$ was not uniform. Due to the large initial rebound ratio, the closer the wall, the smaller the amount of coarse aggregate. Hence, in terms of the shotcrete with thin layer $\left(x_{1}\right)$, in order to form a standard concrete specimen with $100 \mathrm{~mm} \times 100 \mathrm{~mm} \times 100 \mathrm{~mm}$, the cutting line on the concrete slab had to pass through the region $(\Delta x)$ that lacked coarse aggregates. For the shotcrete with thick sprayed layer $\left(x_{2}\right)$, the cutting position of concrete slab was relatively reasonable where coarse aggregate distribution was uniform. It was assumed that the coarse aggregate distribution that related the build-up thickness affected the mechanical properties of shotcrete.

3.3.4. Other Relationships. According to Figures 17 and 18, it was hard to find the obvious relationship between pressure 
drop and build-up thickness, as well as the relationship between compressive and splitting strengths. However, in the reports $[13,77]$, the compressive strength of concrete without mixing fibers was proportional to the splitting strength. According to analysis, in these tests, the effect of mixed PET fibers on compressive strength was not significant but on splitting strength was significant, especially for the changes of length and content of PET fiber. As shown in Figures 9 and 11, with increasing length or content of PET fiber, the change of compressive strength is small while the splitting strength is increased largely. Hence, mixing PET fibers disturbed the linear relationship between compressive strength and splitting strength of concrete. In the next study, those relationships would be further explored with a lot of specimens, and at the same time, the PET fiber parameters should be considered. This research can provide a theoretical basis for shotcrete in mine. High quality wet-mix shotcrete with PET fiber can effectively reduce mine disasters, such as dust and roof accidents [78-95].

\section{Conclusions}

In order to investigate the effects of PET fiber parameters on the pumpability, shootability, and mechanical properties of wet-mix shotcrete, the orthogonal test was conducted. The change trends of shotcrete properties with increasing PET fiber length, width, and content were revealed. In addition, relationships between slump, pumpability, shootability, and mechanical properties were explored. The final PET fiber parameters used for wet-mix shotcrete were determined (i.e., $1 \mathrm{~mm}$ width, $20 \mathrm{~mm}$ length, and $5 \mathrm{~kg} / \mathrm{m}^{3}$ content). The main conclusions are as follows:

(1) Increasing PET fiber width increased the slump and pressure drop but reduced the compressive strength; increasing PET fiber length reduced the slump and pressure drop but increased the build-up thickness; increasing PET fiber content reduced the slump but increased the pressure drop, build-up thickness, and splitting strength.

(2) The slim PET fiber tended to agglomerate concrete aggregates, reducing the slump and pressure drop but increasing the build-up thickness. The wide PET fiber with smooth surface promoted the slip effect between aggregates, resulting in the weak adhesion between PET fibers and concrete matrix. The increased contact area of wide PET fiber did not improve the mechanical strength.

(3) According to the contribution percentage of ANOVA analysis, PET fiber length was the most influencing factor on slump, build-up thickness, and splitting strength with $57.91 \%, 62.6 \%$, and $67.54 \%$ contribution, respectively. PET fiber width was the most effective parameter on the pressure drop and compressive strength with $80.24 \%$ and $90.21 \%$ contribution, respectively. The significant factor that appeared frequently was PET fiber width, especially for pressure drop and compressive strength.
(4) According to the correlation analysis, the compressive and splitting strength showed a downward trend with the increase of pressure drop. The corresponding fitting effect between pressure and compressive strength was best among all fitting functions with variance 0.8482 . The build-up thickness had less effect on compressive strength while it had relatively obvious effect on splitting strength.

\section{Data Availability}

The data used to support the findings of this study are available from the corresponding author upon request.

\section{Conflicts of Interest}

The authors declare that they have no conflicts of interest.

\section{Acknowledgments}

This study was funded by projects such as the National Key Research and Development Plan of the 13th Five-Year Period (Grant number 2017YFC0805203); National Natural Science Foundation of China (Grant nos. 51604163 and 51974177); Shandong Key Research and Development Program (Grant number 2018GSF116001); Natural Science Foundation of Shandong (Grant numbers ZR2019QEE007, ZR201801280006, and ZR2019MEE115); and Project of Shandong Province Higher Educational Science and Technology Program (Grant number J15LH03).

\section{References}

[1] I. Galan, A. Baldermann, W. Kusterle, M. Dietzel, and F. Mittermayr, "Durability of shotcrete for underground support-review and update," Construction and Building Materials, vol. 202, pp. 465-493, 2019.

[2] G. Duarte, M. Bravo, J. de Brito, and J. Nobre, "Mechanical performance of shotcrete produced with recycled coarse aggregates from concrete," Construction and Building Materials, vol. 210, pp. 696-708, 2019.

[3] Z. Shaowei, O. Gaolong, L. CHunming, and L. Fuxin, "Tension anchorage of reinforced concrete beams strengthened with prestressed CFRP plates," Journal of Shandong University of Science and Technology (Natural Science), vol. 34, no. 5, pp. 27-31, 2015.

[4] P. Li, Z. Zhou, L. Chen, G. Liu, and W. Xiao, "Research on dust suppression technology of shotcrete based on new spray equipment and process optimization," Advances in Civil Engineering, vol. 2019, Article ID 4831215, 11 pages, 2019.

[5] L. Chen and G. Liu, "Airflow-dust migration law and control technology under the simultaneous operations of shotcreting and drilling in roadways," Arabian Journal for Science and Engineering, vol. 44, no. 5, pp. 4961-4969, 2019.

[6] K. Huang, X. Shi, D. Zollinger, M. Mirsayar, A. Wang, and L. Mo, "Use of $\mathrm{MgO}$ expansion agent to compensate concrete shrinkage in jointed reinforced concrete pavement under high-altitude environmental conditions," Construction and Building Materials, vol. 202, pp. 528-536, 2019. 
[7] P.-m. Zhan and Z.-h. He, "Application of shrinkage reducing admixture in concrete: a review," Construction and Building Materials, vol. 201, pp. 676-690, 2019.

[8] J. Zhang, L. Liu, Q. Li et al., "Development of cement-based self-stress composite grouting material for reinforcing rock mass and engineering application," Construction and Building Materials, vol. 201, pp. 314-327, 2019.

[9] J. Zhang, L. Liu, J. Cao, X. Yan, and F. Zhang, "Mechanism and application of concrete-filled steel tubular support in deep and high stress roadway," Construction and Building Materials, vol. 186, pp. 233-246, 2018.

[10] L. A. G. Bitencourt, O. L. Manzoli, T. N. Bittencourt, and F. J. Vecchio, "Numerical modeling of steel fiber reinforced concrete with a discrete and explicit representation of steel fibers," International Journal of Solids and Structures, vol. 159, pp. 171-190, 2019.

[11] F. J. Baldenebro-Lopez, J. H. Castorena-Gonzalez, J. I. Velazquez-Dimas et al., "Influence of continuous plastic fibers reinforcement arrangement in concrete strengthened," IOSR Journal of Engineering, vol. 4, no. 4, pp. 15-23, 2014.

[12] G. Liu, W. Cheng, and L. Chen, "Investigating and optimizing the mix proportion of pumping wet-mix shotcrete with polypropylene fiber," Construction and Building Materials, vol. 150, pp. 14-23, 2017.

[13] W. Cheng, G. Liu, and L. Chen, "Pet fiber reinforced wet-mix shotcrete with walnut shell as replaced aggregate," Applied Sciences, vol. 7, no. 4, p. 345, 2017.

[14] R. K. Padhan and A. A. Gupta, "Preparation and evaluation of waste PET derived polyurethane polymer modified bitumen through in situ polymerization reaction," Construction and Building Materials, vol. 158, pp. 337-345, 2018.

[15] C. Marthong and D. K. Sarma, "Influence of PET fiber geometry on the mechanical properties of concrete: an experimental investigation," European Journal of Environmental and Civil Engineering, vol. 20, no. 7, pp. 771-784, 2016.

[16] Y. Ren, J. Tian, Y. Liu, and C. Du, "Nonlinear deformation, thermal buckling and vibration of SMA fiber composite beams," Journal of Shandong University of Science and Technology (Natural Science), vol. 38, no. 1, pp. 99-110, 2019.

[17] J. Irwan, R. Asyraf, N. Othman, K. H. Koh, M. M. K. Annas, and S. Faisal, "The mechanical properties of PET fiber reinforced concrete from recycled bottle wastes," Advanced Materials Research, vol. 795, pp. 347-351, 2013.

[18] T. Ochi, S. Okubo, and K. Fukui, "Development of recycled PET fiber and its application as concrete-reinforcing fiber," Cement and Concrete Composites, vol. 29, no. 6, pp. 448-455, 2007.

[19] D. Foti, "Preliminary analysis of concrete reinforced with waste bottles PET fibers," Construction and Building Materials, vol. 25, no. 4, pp. 1906-1915, 2011.

[20] D. Foti, "Recycled waste PET for sustainable fiber-reinforced concrete," in Use of Recycled Plastics in Eco-Efficient Concrete, F. Pacheco-Torgal, J. Khatib, F. Colangelo, and R. Tuladhar, Eds., Woodhead Publishing, Sawston, UK, pp. 387-410, 2019.

[21] E. L. Pereira, A. L. de Oliveira Junior, and A. G. Fineza, "Optimization of mechanical properties in concrete reinforced with fibers from solid urban wastes (PET bottles) for the production of ecological concrete," Construction and Building Materials, vol. 149, pp. 837-848, 2017.

[22] D. Foti and F. Paparella, "Impact behavior of structural elements in concrete reinforced with PET grids," Mechanics Research Communications, vol. 57, no. 2, pp. 57-66, 2014.
[23] D. Foti, "Innovative techniques for concrete reinforcement with polymers," Construction and Building Materials, vol. 112, pp. 202-209, 2016.

[24] S. Faisal, J. Irwan, N. Othman, and M. W. Ibrahim, "Flexural toughness of ring-shaped waste bottle fiber concrete," MATEC Web of Conferences, vol. 47, p. 01002, 2016.

[25] S. Fadhil and M. Yaseen, "The production of economical precast concrete panels reinforced by waste plastic fibers," American Journal of Civil Engineering and Architecture, vol. 3, no. 3, pp. 80-85, 2015.

[26] W. M. N. W. A. Rahman and A. F. A. Wahab, "Green pavement using recycled polyethylene terephthalate (PET) as partial fine aggregate replacement in modified asphalt," Procedia Engineering, vol. 53, pp. 124-128, 2013.

[27] Z. Dehghan and A. Modarres, "Evaluating the fatigue properties of hot mix asphalt reinforced by recycled PET fibers using 4-point bending test," Construction and Building Materials, vol. 139, pp. 384-393, 2017.

[28] J. Fang, Q. Liu, H. Zang, Q. Fu, X. Cao, and X. Lv, "Performance of a polyacrylonitrile fiber bundle on the filtration of inhalable particles," Journal of Shandong University of Science and Technology (Natural Science), vol. 37, no. 6, pp. 30-37, 2018.

[29] F. S. Khalid, J. M. Irwan, M. H. Wan Ibrahim, N. Othman, and S. Shahidan, "Splitting tensile and pullout behavior of synthetic wastes as fiber-reinforced concrete," Construction and Building Materials, vol. 171, pp. 54-64, 2018.

[30] K. P. Juhász and V. Kis, "The effect of the length of macro synthetic fibres on their performance in concrete," IOP Conference Series Materials Science and Engineering, vol. 246, no.1, Article ID 012027, 2017.

[31] A. Beglarigale and H. Yazıc1, "Pull-out behavior of steel fiber embedded in flowable RPC and ordinary mortar," Construction and Building Materials, vol. 75, pp. 255-265, 2015.

[32] A. E. Richardson and S. Landless, "Synthetic fibres and steel fibres in concrete with regard to bond strength and toughness," Northumbria Working Paper Series: Interdisciplinary Studies in the Built and Virtual Environment, vol. 2, no. 2, pp. 128-140, 2009.

[33] A. J. Babafemi and W. P. Boshoff, "Tensile creep of macrosynthetic fibre reinforced concrete (MSFRC) under uni-axial tensile loading," Cement and Concrete Composites, vol. 55, pp. 62-69, 2015.

[34] M. G. Alberti, A. Enfedaque, and J. C. Gálvez, "On the mechanical properties and fracture behavior of polyolefin fiberreinforced self-compacting concrete," Construction and Building Materials, vol. 55, no. 4, pp. 274-288, 2014.

[35] J. Irwan, N. Othman, K. H. Koh et al., "Development of mix design nomograph for polyethylene terephthalate fiber concrete," Applied Mechanics and Materials, vol. 253-255, pp. 408-416, 2013.

[36] S. B. Kim, N. H. Yi, H. Y. Kim, J.-H. J. Kim, and Y.-C. Song, "Material and structural performance evaluation of recycled PET fiber reinforced concrete," Cement and Concrete Composites, vol. 32, no. 3, pp. 232-240, 2010.

[37] Z. Zhou, L. Chen, Y. Zhao, T. Zhao, X. Cai, and X. Du, "Experimental and numerical investigation on the bearing and failure mechanism of multiple pillars under overburden," Rock Mechanics \& Rock Engineering, vol. 50, no. 4, pp. 9951010, 2017.

[38] L. Jiang, P. Zhang, L. Chen et al., "Numerical approach for goaf-side entry layout and yield pillar design in fractured ground conditions," Rock Mechanics \& Rock Engineering, vol. 50, no. 11, pp. 3049-3071, 2017. 
[39] S. Li, G. Zhou, Y. Wang, B. Jing, and Y. Qu, "Synthesis and characteristics of fire extinguishing gel with high water absorption for coal mines," Process Safety and Environmental Protection, vol. 125, pp. 207-218, 2019.

[40] J. Wang, G. Zhou, X. Wei, and S. Wang, "Experimental characterization of multi-nozzle atomization interference for dust reduction between hydraulic supports at a fully mechanized coal mining face," Environmental Science and Pollution Research, vol. 26, no. 10, pp. 10023-10036, 2019.

[41] Q. Liu, W. Nie, Y. Hua, H. Peng, C. Liu, and C. Wei, "Research on tunnel ventilation systems: dust diffusion and pollution behaviour by air curtains based on CFD technology and field measurement," Building and Environment, vol. 147, pp. 444-460, 2019.

[42] C. Xu, W. Nie, Z. Liu, H. Peng, S. Yang, and Q. Liu, "Multifactor numerical simulation study on spray dust suppression device in coal mining process," Energy, vol. 182, pp. 544-558, 2019.

[43] W. Zhou, W. Nie, C. Liu et al., "Modelling of ventilation and dust control effects during tunnel construction," International Journal of Mechanical Sciences, vol. 160, pp. 358-371, 2019.

[44] Z. Xiu, W. Nie, D. Chen et al., "Numerical simulation study on the coupling mechanism of composite-source airflow-dust field in a fully mechanized caving face," Powder Technology, vol. 356, pp. 443-457, 2019.

[45] P. Cai, W. Nie, D. Chen, S. Yang, and Z. Liu, "Effect of air flowrate on pollutant dispersion pattern of coal dust particles at fully mechanized mining face based on numerical simulation," Fuel, vol. 239, pp. 623-635, 2019.

[46] Z.-X. Hu, X.-M. Hu, W.-M. Cheng, Y.-Y. Zhao, and M.-Y. Wu, "Performance optimization of one-component polyurethane healing agent for self-healing concrete," Construction and Building Materials, vol. 179, pp. 151-159, 2018.

[47] N. Guanhua, D. Kai, L. Shang, and S. Qian, "Gas desorption characteristics effected by the pulsating hydraulic fracturing in coal," Fuel, vol. 236, pp. 190-200, 2019.

[48] G. Wang, X. Qin, J. Shen, Z. Zhang, D. Han, and C. Jiang, "Quantitative analysis of microscopic structure and gas seepage characteristics of low-rank coal based on CT threedimensional reconstruction of CT images and fractal theory," Fuel, vol. 256, Article ID 115900, 2019.

[49] G. Wang, C. Jiang, J. Shen, D. Han, and X. Qin, "Deformation and water transport behaviors study of heterogenous coal using CT-based 3D simulation," International Journal of Coal Geology, vol. 211, Article ID 103204, 2019.

[50] L. Zhen, Y. He, W. Wang, W. Cheng, and X. Lin, "Experimental study on the pore structure fractals and seepage characteristics of a coal sample around a borehole in coal seam water infusion," Transport in Porous Media, vol. 125, no. 2, pp. 289-309, 2018.

[51] X. Lin, Z. T. Wang, W. Gang et al., “Technological aspects for underground coal gasification in steeply inclined thin coal seams at Zhongliangshan coal mine in China," Fuel, vol. 191, pp. 486-494, 2017.

[52] Z. Song, J. Hao, Y. Shi, J. Tang, and J. Liu, "An overview of connotation and development of practical ground pressure control theory," Journal of Shandong University of Science and Technology (Natural Science), vol. 38, no. 1, pp. 1-15, 2019.

[53] G. Wang, J. Shen, S. Liu, C. Jiang, and X. Qin, “Three-dimensional modeling and analysis of macro-pore structure of coal using combined X-ray CT imaging and fractal theory," International Journal of Rock Mechanics and Mining Sciences, vol. 123, Article ID 104082, 2019.
[54] K.-K. Yun, P. Choi, and J. H. Yeon, "Predicting pumpability and shootability of crushed aggregate wet-mix shotcrete based on rheological properties," Advances in Materials Science and Engineering, vol. 2016, Article ID 9838213, 9 pages, 2016.

[55] M. Khooshechin and J. Tanzadeh, "Experimental and mechanical performance of shotcrete made with nanomaterials and fiber reinforcement," Construction and Building Materials, vol. 165, pp. 199-205, 2018.

[56] R. K. Roy, A Primer on Taguchi Method, Society of Manufacturing Engineers, Dearborn, MI, USA, 1990.

[57] E. Secrieru, S. Fataei, C. Schröfl, and V. Mechtcherine, "Study on concrete pumpability combining different laboratory tools and linkage to rheology," Construction and Building Materials, vol. 144, pp. 451-461, 2017.

[58] K.-K. Yun, S.-Y. Choi, and J. H. Yeon, "Effects of admixtures on the rheological properties of high-performance wet-mix shotcrete mixtures," Construction and Building Materials, vol. 78, pp. 194-202, 2015.

[59] K.-K. Yun, P. Choi, and J. H. Yeon, "Correlating rheological properties to the pumpability and shootability of wet-mix shotcrete mixtures," Construction and Building Materials, vol. 98, pp. 884-891, 2015.

[60] D. Beaupre, Rheology of high performance shotcrete, Ph.D. thesis, University of British Columbia, Vancouver, Canada, 1994.

[61] J. Armengaud, G. Casaux-Ginestet, M. Cyr, B. Husson, and M. Jolin, "Characterization of fresh dry-mix shotcrete and correlation to rebound," Construction and Building Materials, vol. 135, pp. 225-232, 2017.

[62] S. A. Austin, C. H. Peaston, and P. J. Robins, "Material and fibre losses with fibre reinforced sprayed concrete," Construction and Building Materials, vol. 11, no. 5-6, pp. 291-298, 1997.

[63] N. Banthia, J. F. Trottier, D. Beaupre, and D. Wood, "Influence of fiber geometry in steel fiber reinforced wet-mix shotcrete," ACI Concrete Int.-Design and Construction, vol. 16, no. 6, pp. 27-32, 1994.

[64] G. Liu, L. Chen, W. Cheng, and Y. Huang, "Research on pump primers for friction reduction of wet-mix shotcrete based on precreating lubricating layer," Advances in Materials Science and Engineering, vol. 2017, no. 3, Article ID 3462074, 12 pages, 2017.

[65] J.-M. Yang, J.-K. Kim, and D.-Y. Yoo, "Performance of shotcrete containing amorphous fibers for tunnel applications," Tunnelling and Underground Space Technology, vol. 64, pp. 85-94, 2017.

[66] W. Jiabin, N. Ditao, and S. Zhanping, "Damage layer thickness and formation mechanism of shotcrete with and without steel fiber under sulfate corrosion of dry-wet cycles by ultrasound plane testing method," Construction and Building Materials, vol. 123, pp. 346-356, 2016.

[67] P. Banfill, Rheology Of Fresh Cement And Concrete, CRC Press, Boca Raton, FL, USA, 1991.

[68] C. Fu, H. Ye, K. Wang, K. Zhu, and C. He, "Evolution of mechanical properties of steel fiber-reinforced rubberized concrete (FR-RC)," Composites Part B: Engineering, vol. 160, pp. 158-166, 2019.

[69] L. Fan, Y. Bao, W. Meng, and G. Chen, "In-situ monitoring of corrosion-induced expansion and mass loss of steel bar in steel fiber reinforced concrete using a distributed fiber optic sensor," Composites Part B: Engineering, vol. 165, pp. 679-689, 2019.

[70] J. Han, M. Zhao, J. Chen, and X. Lan, "Effects of steel fiber length and coarse aggregate maximum size on mechanical 
properties of steel fiber reinforced concrete," Construction and Building Materials, vol. 209, pp. 577-591, 2019.

[71] R. S. Olivito and F. A. Zuccarello, "An experimental study on the tensile strength of steel fiber reinforced concrete," Composites Part B: Engineering, vol. 41, no. 3, pp. 246-255, 2010.

[72] L. Chen, G. Liu, W. Cheng, and G. Pan, "Pipe flow of pumping wet shotcrete based on lubrication layer," Springerplus, vol. 5, no. 1, pp. 1-14, 2016.

[73] G. Liu and L. Chen, "Development of a new type of green switch air entraining agent for wet-mix shotcrete and its engineering application," Advances in Materials Science and Engineering, vol. 2016, Article ID 6981091, 9 pages, 2016.

[74] A. K. H. Kwan and W. W. S. Fung, "Effects of SP on flowability and cohesiveness of cement-sand mortar," Construction and Building Materials, vol. 48, no. 19, pp. 1050-1057, 2013.

[75] B. Boulekbache, M. Hamrat, M. Chemrouk, and S. Amziane, "Flowability of fibre-reinforced concrete and its effect on the mechanical properties of the material," Construction and Building Materials, vol. 24, no. 9, pp. 1664-1671, 2010.

[76] M. S. Choi, Y. J. Kim, K. P. Jang, and S. H. Kwon, "Effect of the coarse aggregate size on pipe flow of pumped concrete," Construction and Building Materials, vol. 66, pp. 723-730, 2014.

[77] J. Wang, D. Niu, and Y. Zhang, "Mechanical properties, permeability and durability of accelerated shotcrete," Construction and Building Materials, vol. 95, pp. 312-328, 2015.

[78] L. Chen, G. Ma, G. Liu, and Z. Liu, "Effect of pumping and spraying processes on the rheological properties and air content of wet-mix shotcrete with various admixtures," Construction and Building Materials, vol. 225, pp. 311-323, 2019.

[79] Q. Liu, W. Nie, Y. Hua et al., "A study on the dust control effect of the dust extraction system in TBM construction tunnels based on CFD computer simulation technology," Advanced Powder Technology, vol. 30, no. 10, pp. 2059-2075, 2019.

[80] L. Chen, P. Li, G. Liu, W. Cheng, and Z. Liu, "Development of cement dust suppression technology during shotcrete in mine of China-a review," Journal of Loss Prevention in the Process Industries, vol. 55, pp. 232-242, 2018.

[81] H. Peng, W. Nie, H. Yu et al., "Research on mine dust suppression by spraying: Development of an air-assisted PM10 control device based on CFD technology," Advanced Powder Technology, vol. 30, pp. 2588-2599, 2019.

[82] G. Pan, P. Li, L. Chen, and G. Liu, "A study of the effect of rheological properties of fresh concrete on shotcrete-rebound based on different additive components," Construction and Building Materials, vol. 224, pp. 1069-1080, 2019.

[83] S. Yin, W. Nie, Q. Liu, and Y. Hua, “Transient CFD modelling of space-time evolution of dust pollutants and air-curtain generator position during tunneling," Journal of Cleaner Production, vol. 239, Article ID 117924, 2019.

[84] N. Guanhua, S. Qian, X. Meng et al., "Effect of NaCl-SDS compound solution on the wettability and functional groups of coal," Fuel, vol. 257, Article ID 116077, 2019.

[85] X. Jingna, N. Guanhua, X. Hongchao, L. Shang, S. Qian, and D. Kai, "The effect of adding surfactant to the treating acid on the chemical properties of an acid-treated coal," Powder Technology, vol. 356, pp. 263-272, 2019.

[86] N. Guanhua, X. Hongchao, L. Shang et al., "The effect of anionic surfactant (SDS) on pore-fracture evolution of acidified coal and its significance for coalbed methane extraction," Advanced Powder Technology, vol. 30, no. 5, pp. 940-951, 2019.

[87] X. Hongchao, N. Guanhua, L. Shang et al., "The influence of surfactant on pore fractal characteristics of composite acidized coal," Fuel, vol. 253, pp. 741-753, 2019.

[88] N. Guanhua, L. Zhao, S. Qian, L. Shang, and D. Kai, "Effects of $[\mathrm{Bmim}][\mathrm{Cl}]$ ionic liquid with different concentrations on the functional groups and wettability of coal," Advanced Powder Technology, vol. 30, no. 3, pp. 610-624, 2019.

[89] L. Xin, W. Cheng, J. Xie, W. Liu, and M. Xu, "Theoretical research on heat transfer law during underground coal gasification channel extension process," International Journal of Heat and Mass Transfer, vol. 142, Article ID 118409, 2019.

[90] X. Ren, X. Hu, D. Xue et al., "Novel sodium silicate/polymer composite gels for the prevention of spontaneous combustion of coal," Journal of Hazardous Materials, vol. 371, pp. 643654, 2019.

[91] M. Wu, X. Hu, Q. Zhang, D. Xue, and Y. Zhao, "Growth environment optimization for inducing bacterial mineralization and its application in concrete healing," Construction and Building Materials, vol. 209, pp. 631-643, 2019.

[92] X. Wang, Y. Zhang, B. Liu, P. Liang, and Y. Zhang, "Effectiveness and mechanism of carbamide/fly ash cenosphere with bilayer spherical shell structure as explosion suppressant of coal dust," Journal of Hazardous Materials, vol. 365, pp. 555-564, 2019.

[93] W. Cheng, Z. Liu, H. Yang, and W. Wang, "Non-linear seepage characteristics and influential factors of water injection in gassy seams," Experimental Thermal and Fluid Science, vol. 91, pp. 41-53, 2018.

[94] X. Wang, X. Huang, X. Zhang, Y. Zhang, and Y. Zhang, "Numerical simulation of coal dust explosion suppression by inert particles in spherical confined storage space," Fuel, vol. 253, pp. 1342-1350, 2019.

[95] B. Kong, E. Wang, Z. Li, and W. Lu, "Study on the feature of electromagnetic radiation under coal oxidation and temperature rise based on multi-fractal theory," Fractals, vol. 27, no. 3, Article ID 1950038, 2019. 


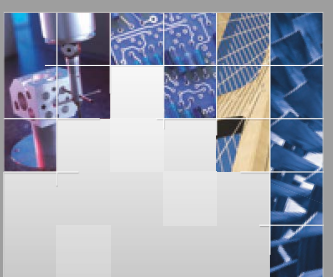

\section{Enfincering}
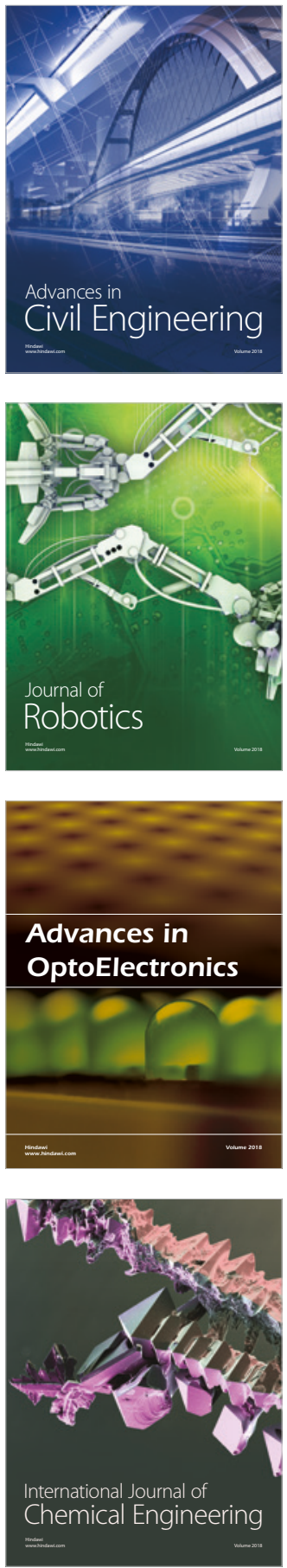

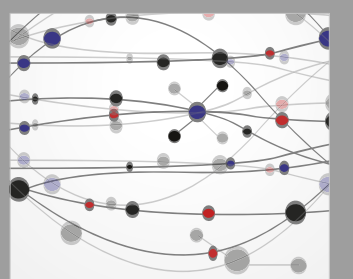

\section{Rotating \\ Machinery}

The Scientific World Journal

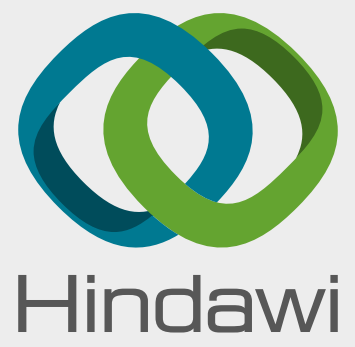

Submit your manuscripts at

www.hindawi.com
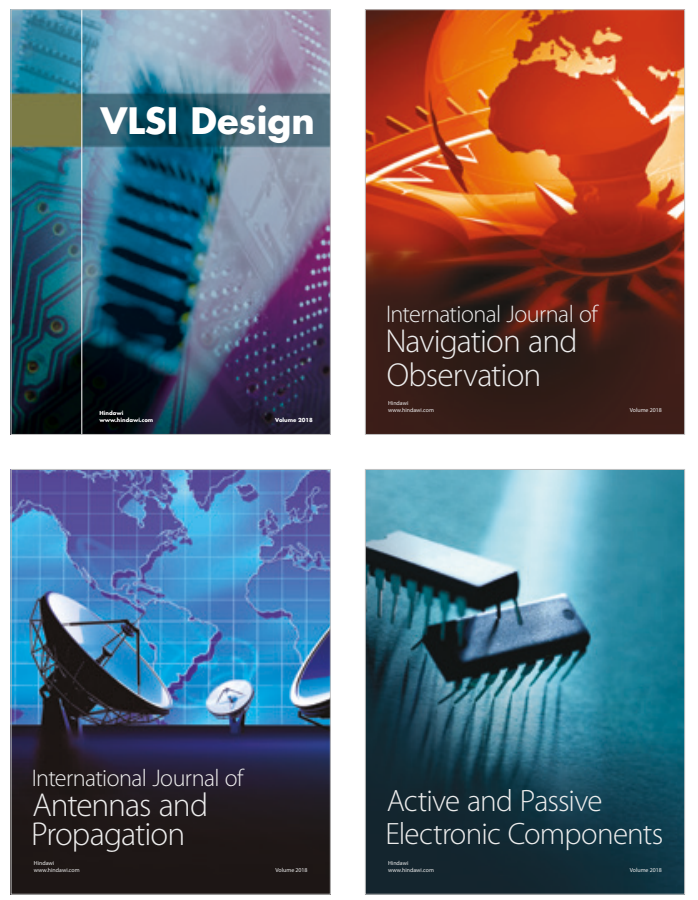
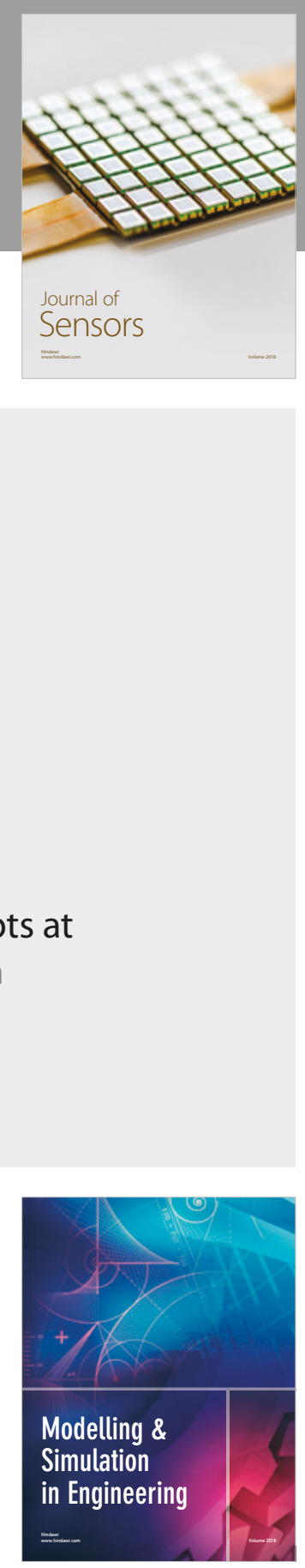

\section{Advances \\ Multimedia}
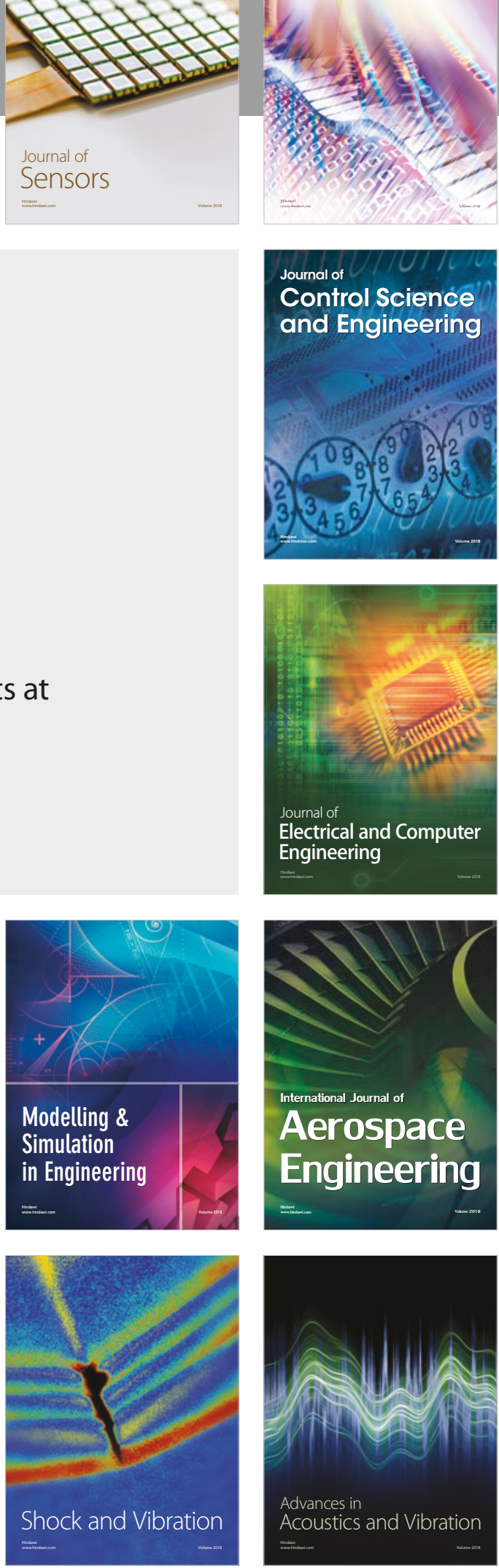